\title{
PSYCHOLOGICAL ADAPTATION.
}

\section{By CONSTANCE LONG1.}

In the Swiss school of analysis we interpret the dream both objectively and subjectively. When the dream symbols represent real objects of love or hate or interest in the outer world and are so understood, and so referred to in the associations of the dreamer, we call the interpretation objective (akin to the "material category" of Silberer ${ }^{2}$ ). This kind of analyeis dissects the dream into its memory elements, and relates them to matters of fact. This is causal interpretation.

Subjective interpretation relates the dream elements to the feelings of the dreamer. In this all the rôles played by the people or things in the dream are regarded as expressions of tendencies or attitudes or views of the dreamer. This approximates to Silberer's 'functional symbolism.' Subjective interpretation is extremely important from the teleological standpoint, for it points to the solution of the individual problem, since the dream as a rule constellates round the most difficult and painful problem of the moment. Both kinds of interpretation are valid. The one is analytic and leads down into the depths of the impulsive life. The other is synthetic, and brings back from the depths the raw material for the purposes of constructive life.

This twofold interpretation fits into the general scheme of life because adaptation is itself twofold, viz. to the inner subjective world of psychic reality, and to the outer objective world of material reality. A certain amount of adaptation to both sides has to be made by every man, and the counter-claims of the two sides are present in all. Inasmuch as the conflict entailed is conscious, society and the individual advance by means of it. Inasmuch as the counter-claims are adjusted by repression, the conflict is thrown into the unconscious, where it is carried on in a manner that robs us of our energy, and withholds from us the possibility of attaining the fruits of our strivings.

Even the most normal person has a good deal of unconscious conflict but he does not break down under it. Perhaps the abnormal physical

1 Read before the Medical Section of the British Psychological Society, April 28, 1920.

2 Silberer, Problems of Mysticiom and its Symboliom. 
factor is lacking, such, for instance, as a brain defect, an organ inferiority, some deficiency or maladjustment of internal secretions, or a pathological blood state. Hyper-sensitive individuals, however, break down under the conflict and develop a neurosis; while still less stable persons may be overwhelmed by the unconscious, and losing their orientation become mentally deranged. There is no conspicuous line of demarcation between these states. They pass insensibly from normal to abnormal, the result differing in degree more than in kind. Questions of physical and psychical inheritance, and questions of social environment all play their part in making up the human being. Whatever factors among the foregoing contribute to the breakdown there will inevitably be found in every neurotic individual a basis of unconscious mental conflict, with a resulting failure in adaptation. All the insoluble problems arise round the unconscious conflict and neurosis is unmistakable evidence of its presence.

The whole object of treatment by psychological analysis is to open up the unconscious mind to the sufferer in such a way that he is enabled to change his relation to it. In addition to the unconscious conflict every case of neurosis also presupposes an introversion of libido, i.e. a turning in of the energizing life current which first over-stimulates the ego feelings, and then regressively animates the phantastic images of the unconscious, giving them a fictitious and even mythical importance.

The analytic treatment does not really consist in getting at a psychical foreign body and letting out psychic pus! There are no foreign bodies in the mind. Everything that is there should be there. It is more a question of bodies in a wrong relation. There are bodies that have been converted into bogies by a process of myth making. There are complexes formed above or below the threshold of consciousness which through dissociation act autonomously. "The past follows us at every instant," says Bergson, "all that we have felt, thought, or willed from our earliest infancy, is there, leaning over the present which is about to join it, pressing against the portals of consciousness that would fain leave it outside." It is the dissociation of the complex that gives it the semblance of a foreign body. It is the unconscious character of the emotion attached to it that gives it its peculiar feeling-tone. The feeling-tone belongs to the phantasies which are associated with the complex. In making these phantasies conscious the way is opened to a new adjustment with reality. It is really rather strange to hear psychotherapists still held by the attractive theory of abreaction which Freud was the first to discard as being far from the root cause of the illness. 
Abreaction opens as it were the first portal of the unconscious. It acts effectively up to a point. Certain resistances are broken down, there is a relief of tension as the emotion is gradually transferred from the unconscious of the patient to the physician. There is a sort of 'absolution' involved, a feeling of having submitted to the collective judgment in the person of the physician, who in the capacity of judge and saviour becomes the helper and redeemer of the new life of effort at whose instigation a fresh adaptation is undertaken. Abreaction works in a crisis. It often allows some of the hidden values of the sufferer to come to realisation so that he can once more get on with life. In so far as it succeeds it does so on account of a leading out into the consciousness the sum of energy-libido-formerly occupied with the complex and by restoring the complex itself to conscious control. This in many cases is all that we as physicians are permitted to do, and also in many cases this is all that we need to do. But do not let us be deceived. Abreaction introduces us merely to the ante-room of the unconscious. We have not - touched the root causes of the dissociation. The general system of phantasies remains unattacked, and indeed it is through the transference of the father or mother image to the physician that the dynamic force for the alleviation is provided. In this connexion I cannot forbear quoting from the Persian of Jamí, since it shows that the value of abreaction was well understood by the Easterns in the fifteenth century. It is called "The Afflicted Poet."

"A poet paid a visit to a doctor and said: "Something has become knotted in my heart which makes me uncomfortable; it makes also my limbs wither, and causes the hairs on my body to stand on end.'

"The physician, who was a shrewd man, asked: 'Very likely thou hast not yet recited to any one thy latest verses.' The poet replied: 'Just so.' The doctor continued: 'Then recite them.' He complied, was requested to repeat them, and again to rehearse them for a third time.

"After he had done so, the doctor said: 'Now arise, for thou art saved. This poetry had become knotted in thy heart, and the dryness of it took effect upon the outside; but as thou hast relieved thy heart, thou art cured."

The recognition that adaptation to the inner reality is as important in human life as adaptation to the outer reality necessarily has very farreaching results on our methods of analysis. The well-being of the individual lies in the adjustment between two sets of equally valid claims. The antagonism between the conscious and unconscious now has the appearance of being a claim for better understanding between the ob- 
jective necessity and the subjective necessity. It is the injustice done to the one or the other that produces a loss of balance and disharmony in the individual. Dreams and phantasies in their subjective significance are not to be regarded solely as the result of repression but also as 'schemes or plans' which have a meaning for the solution of the problems of the moment. They are corrective and compensatory to the merely external view. Thus regarded, the analogical character of the dream is estimated and the manifest content is credited with an important meaning. The teleological purpose of the dream gives it a moral value, for it has to do not only with our origins but also with our destiny. It is really easy to understand why the Viennese school repudiates analysis that on one side is based on the teleological value of the phantasies. If the unconscious is regarded as the all-round inferior mind, then every demand it makes will be resisted as an intrusion, producing hostile feelings analogous to those innate prejudices seen in class warfare. If, on the other hand, the unconscious is regarded also as the creative mind then we shall allow that it has claims upon our attention; at least as great as those that belong to the world of created things-and that it works constantly for our good as well as for our undoing.

I propose to approach the question of adaptation from the point of view of the psychological types into which men are grouped collectively. That is to say, men are born into a type just as they are born into a family. Latterly in the psychological analysis of my patients I have mentally divided them into two main classes-viz. those who are orientated to the unconscious, and those who are orientated to the conscious. This is actually a different division from the types of introversion and extraversion already described to us by $\mathrm{Dr}$ Jung, although it arises out of it. In his further work on types Dr Jung has discriminated four types, dividing them into groups under the four psychological functions of thinking, feeling, intuition, and sensation. Two of these types adapt themselves to life by processes we call rational, viz. the introverted type by thinking, and the extraverted type by feeling. The other two adapt themselves by instinctive and unconscious processes, viz. by intuition and sensation, that is to say by non-rational processes. Dr Jung has been working on the types for several years. He was early aware that the two types he first described included others, and he is about to publish a book dealing with this subject. I have often talked with him on this matter, and also with other analysts, notably Miss Maria Moltzer of Zürich, and Dr Beatrice Hinkle of New York.

What follows, however, belongs to my personal understanding of the 
types, and is verified in my personal experience with my patients, and must not be taken definitely as Dr Jung's views. It has become habitual for me to work with the types in the back of my mind, and I have found it so illuminating that I cannot forbear to introduce the subject.

The above names of types are abstract definitions, which are too abstract for reality. The ideal type only exists in pathological states, since an over-accentuated type-development involves such severe repressions as can only occur in neurotic or psychotic forms. Most people have mixed qualities; their main tendency, and their most highly adapted function is indicated in their type-name.

In the introverted or thinking type the preservation of the ego is all important. The ego is the object of the libido; it is the real value, and the flow of libido is centripetal. This type turns naturally to philosophical thinking, and by abstracting the idea from the object gives the chief place to the concept. It appreciates the external object in retiring from it and thinking about it. The thinking is well adapted but the feelings are introverted and repressed and relatively inaccessible. The claims of the object are discounted because they threaten the integrity of the ego. The repressed and unconscious feelings tend to be projected and have a personal character. This type is embarrassed when it is suddenly confronted with a situation wherein thought offers no solution. Examples of statesmen of this type are President Wilson and Mr Asquith. 'Wait and see' is really typical of the introvert's method. It means, wait till I have been able to detach myself from this concrete situation, wait till I have been able to think it out. Sight, for this type, means arriving at the abstract idea - not infrequently too late for use. It gives an appearance of stubbornness to the psychology. The feelings are really too 'tender' (to use Prof. James' word) to bear the strain of close contact with the external object, and are kept out of the business.

In the extraverted type the external world is the object of the libido, the current of interest being centrifugal. They love the world and the people and things that are in the world, from which feelings the ego gains enhancement. This type understands the object by a feeling relation with it. The aim is love rather than power, or the attainment of power through the preservation of the object. The thought function in this type is relatively unconscious, hence the thoughts tend to be projected on to the object. When the thought function is trained it turns naturally to science. This type is embarrassed when it is suddenly confronted with a situation which feeling cannot solve. The late President Roosevelt is an example of this type, also Mr Lloyd George, although the 
latter inclines to the intuitive type to be described later. Lloyd George is in a sense very accessible because he goes close up to persons and to the situation in order to feel himself into it. At the same time he lacks the quality of abstract thinking; acting first somewhat impulsively and thinking later, he produces the effect of changeability.

It is interesting to note that the late Furneaux Jordan, F.R.C.S., in a book published in 1886 called Anatomy and Physiology in Character, described two types under the rather unfortunate names of Shrewish and Non-shrewish, names which applied equally to both sexes. It is not difficult to see that they approximate to the extraverted and introverted types respectively, although without any consideration of the compensatory co-function.

In the subconscious types, viz. the intuitive and sensational, the unconscious is the object of the libido. The psychology here is subjective and like the primitive's. The mode of adaptation natural to these types has been rendered of secondary importance in the process of evolution, by the development of rational thought. We give too little credit to-day to intuition for the excellent reason that it has often led us astray. It perceives but does not judge. It is not sense perception which leads to consciousness but intuitive perception which leads to the unconscious. We need a new approach to it through a better understanding, for as Bergson reminds us "although intuition transcends intellect, it is by means of intellect that it has grown beyond the limitations of mere instinct ${ }^{1 . "}$ The subconscious types react less to the external world than to a subjective image of that world. In these types intuition and sensation bear the same relation to each other that thinking and feeling occupy in the rational types. The strictly intuitive person represses sensation, and the extreme sensationalist intuition; they are co-functions mutually corrective and compensatory.

Artists naturally belong to these types, although not exclusively so. The artist is essentially a medium of the unconscious. His works do not come out of nothing. Where he is not otherwise inhibited he projects his unconscious into creative forms by the use of bis symbolic function. In this way we get work of the greatest universal value on the one hand, and on the other of the very smallest merit, and of a very 'personal' kind. In the absence of an expression which can work itself out in art, or some other form, for such persons the unconscious is apt to create compulsions.

Walt Whitman is a pertinent example of a subconscious type at its

1 Ruhe and Paul, Henri Bergaron, p. 225. 
apogee of self-consciousness. He begins a poem called Walt Whitman in this way:

"I celebrate myself;

And what I aseume you shall assume;

For every atom belonging to me, as good belongs to you.

Stop this day and night with me, and you sbiall possess the origin of all poems;

You shall possess the good of the earth and sun (there are millions of suns left);

You shall no longer take things at second or third hand, nor look through the eyes of the dead, nor feed on spectres in books;

You shail not look through my eves either, nor take things from me:

You shall listen to all sides, and filter them from yourself."

It is characteristic of the subconscious types that they find great difficulty in adapting themselves to the demands of society. They are impatient of responsibility, and perpetually come to grief over such matters as money and marriage. They find fetters where other men find incentives. This perhaps accounts for the necessity such a poetphilosopher as Walt Whitman feels to stress the object; he says:

"I will go to the bank by the wood, and become undisguised and naked:

I am mad for it to be in contact with me."

As if his intuition needs that contact with passion to attain a sense of reality. Again he says:

"Welcome is every organ and attribute of me, and of any man hearty and clean;

Not an inch, nor a particle of an inch, is vile, and none shall be lese familiar than the rest."

Unredeemed, these types are unstable in their human relations, because in so far as they are orientated to the unconscious, they are cut off from being understood or from understanding the rational types. The primordial images and instincts comprised in the collective unconscious are more valid for them than the external world, and form the scarcely corrected basis of their impulsive ideas and actions.

For the sensational type the instinct side of the unconscious forms the object. Unless they are under the sway of some passionate emotion they hardly feel themselves to be alive. Unless their contact with others is productive of sensational effect they hardly realise the fact of the other's existence. Perhaps these people express themselves most happily in the histrionic arts and dancing. Under this denomination cases of extreme sadism and masochism belong, and here also we may expect to find those patients whose physical sensations play the chief $r o b l e-s u c h$, for instance, as a hypochondriac whose life is dominated by a disgusting taste in the mouth, or a subjective odour. A psychotic patient of mine 
recently refused to take food because directly she swallowed it she felt it creeping about under her skin, and passing down her arms and legs. In this class the mental conflict is expressed in bodily sensations.

Imperative and impulsive thoughts belong more especially to the intuitional type, because they are influenced by the primordial images which, if uncorrected by reality, produce obsessions of the mind. These instinct-forms of thought enter the mind with terrible power, and are accepted without judgment or evaluation. A certain patient has a phobia of murder germs. She claims to have been infected by buying clothing from a shop where a murder was committed. She has burnt hundreds of pounds' worth of clothes because they came from this place, or have been touched by infected things. The mere utterance of the word 'murder' infects the environment. Anything that touches a newspaper is contaminated if the word is there. She counteracts the effect of the murder germs by countless rituals, and is actuated by the principles of totem and taboo.

Short of a compulsion neurosis, which is the typical neurosis for this type, there is a great tendency to form identification. Adaptation to the external world by means of identification with a parent or a friend, or a teacher, is fairly common. Such persons are driven to express their emotions in others and in the collective because they have found no channel of individual expression in the objective world. They act as the parent acts, feel as the friend or husband feels, and get on pretty well till something disturbs the adaptation. By an unconscious pose the reactions of another personality may be successfully followed. The subjective types appear to be exquisitely sympathetic owing to their ability to project or introject. This is productive of perfect harmony so long as the relation lasts. But when separation befalls through the occurrence of conflicting interests or unforeseen circumstances, the pulling apart is a painful affair. The one being orientated to the conscious, the other to the unconscious, or both being related to different aspects of the unconscious, reconciliation becomes very difficult because they are always talking about the same thing from a different angle. The separation is as complete as the former identification was complete.

We get a picture of an individual of the intuitive type from the able pen of Mr Clutton Brock in his book Shelley the Man and the Poet. He writes as follows: "Shelley was scarcely aware of imperfection in himself; and when he found it in others and in external circumstances it seemed to him to be inexplicable evil, which ought to be, not improved, but abolished. Thus there is some excuse for those admirers who think 
him perfect, and some for those of his contemporaries who thought him a fiend incarnate. There was, or appeared to be, no conflict between different parts of his nature, but only a conflict between his nature and the world outside him ${ }^{1}$. He saw that such a conflict existed, but thought it was produced altogether by some external tyranny, or some inexplicable perversity in man. There seemed to be a perfect harmony in himself, so he thought perfect harmony was possible in the world if it would only get rid of those inhibitions which express men's consciousness of an existing discord.... He never in the course of his short life attained to a full consciousness of himself.... He loved people, not for themselves, but for what he thought of them. He was like those artists who paint the ideal of their own imaginations, not the excellence and promise of the real things."

Difficulties for this type arise in another way also, viz. from the animation of the pairs of opposites. As an example: an artist friend of mine had a good deal of success as an academic painter. This success made him feel cheap. He thought himself not to be following his highest feeling for art, whereupon he relinquished the academic style for a less popular one. He was soon reduced to poverty. Now the value of money naturally assumed great importance because it was, in a manner of speaking, in the unconscious, whereupon he indicts society which ought to endow him and allow him a few hundreds a year, in order that he might repay it with works of art. Lo and behold, a modicum of success came to him! Whereupon he declared himself hampered by it. He needs must once more burn his boats and go to a new country where he had to begin all over again. To the onlooker this conduct is completely irrational, but with this type the accent of value always moves to the pole which is in the unconscious. They are animated by the pairs of opposites, but without the morbid effects that one sees in the neurotic, in whom the pairs of opposites are more or less violently torn asunder, and in whom regression of the libido to the unconscious is a pathological condition. Incidentally we owe things of great value to this type. They are of more value to us than they are to themselves. They interpret our hidden selves to us, and enlarge our perceptions. They have the run of the unconscious, but as a gift, and not by personal differentiation. One has only to instance Shelley's work to recognise that on the creative side the type needs no apologist. It is perhaps what might be called a feminine type, not that it really belongs more to woman than man, but it contains tendencies that are somewhat arbitrarily called feminine.

1 The italica are mine. 
Some of us who study the types ${ }^{1}$ come to the conclusion that people are even more unlike in their mental or emotional reactions on account of type than on account of sex. Speaking from the standpoint of an analyst one can reckon more certainly on the way a person of marked type will behave than on the way he will behave because he is a man. There are necessarily certain conventional reactions he adopts on account of sex which do not really belong to his individual character at all.

Philosophers like Bergson and Kidd lay enormous stress upon intuition. Indeed intuition often finds a way where every other psychological function fails to find one, the reason being that there are times when a completely new adaptation is needed, when the primordial images mixed into the other functions give a value to the idea which fits the unique occasion. Kidd says in his Science of Power, "It is the mind of woman that is destined to take the lead in the future of civilization as the principal instrument of Power." Personally I think he is mistaken in thinking that the future redemption of the world is with woman qua woman. It is rather with the feminine principle, the fructifying power of those who will nourish the seed of the future in patience, who will submit to the burdens of to-day in order that the new era shall arise. Schopenhauer's indictment of woman that "The race is always more to her than the individual," shows the hostility of the rational intellectual thinker against the super-validity, on many occasions, of the intuitive perceptions which reach beyond the present. The psychological bisexuality of the human being permits each person to carry within himself a male and female partner, an intellectual $v$. an intuitive function, a conscious rational $v$. an unconscious non-rational judgment. There is a radical hostility between the two, they are pairs of opposites. The hostility is constantly projected into consciousness, as in Schopenhauer's case. He makes an image of woman-which has many of the characteristics of the Terrible Mother of mythology. The same is true of Otto Weininger. Just as this conflict between the sexes has to be resolved in the process of individuation, so the opposing psychological functions have to be united in a new harmony. Our present-day civilization is tormented with problems for which there appears to be no rational solution. Perhaps it is to the more primitive function of

2 Following in a discussion with G. Stanley Hall, Ph.D. on "Points of difference between Men and Women," Dr Beatrice Hinkle said: "It is a very large and intimate analytical experienos of the lives of men and women that has forced me away from thinking of people according to sex, and led me to the substitution of types instead. When an individual consults me my collective classification is not sexual, but is determined by the answer to $\mathrm{my}$ mentel question, "To what type does he or she belong?"' 
intuition that we must return, with the added wisdom that centuries of scientific thinking have given us.

The study of the Primitive has become of immense importance to us, perhaps because we dimly feel we have lost as well as gained something in the process of evolution and we half realise in him the prototype of our own subconscious man, a being for whom the unknown is full of magic, who can be withered by the evil eye, or stricken dead by fear. Dr Rivers' said in the inaugural address of this ,Section: "There is a general agreement that in neurosis and psychosis there is in action a process of regression to primitive and infantile states.... In so far as the thought and behaviour of savage man are primitive, they furnish material which helps us to understand and to deal with regressive states exhibited by sufferers from disorder of mental functions." He went on to say that medicine standing alone and ethnology standing alone are helpless, but bases wide hopes upon the union of these lines of research. It seems to me that the union will be found in a closer and deeper study applied to the unconscious mind itself through personal experience of it, but only when we can detach ourselves from the idea that we have yet learnt all its laws, or even that we have followed to their conclusion those we begin to understand. We certainly need a wider conception of the unconscious than that which believes it to be only the result of repression. In the view of the unconscious that I follow it would be impossible to acquiesce in Dr Jones's statement that "only what is repressed is symbolised ; only what is repressed needs to be symbolised 2." This is a necessary correlate of the Freudian view of the unconscious. Jung's view of the unconscious is different.

Dr Jung dealt at some length with his formulation of the Collective and Personal Unconscious at the Symposium on "Instinct and the Unconscious" held in London last Summer (1919). As the foregoing ideas about the necessity of adaptation to the inner as well as the outer are related to this conception of the unconscious you will perhaps forgive me if $I$ remind you of his views ${ }^{3}$. Jung's formulation is a conception of the collective psyche as that which embraces collective thought or collective. mind, and collective feeling or herd soul. All these contents are universal and impersonal, they are inherited and potentially present in everyone. It is the unconditioned, undifferentiated basis of all, the "mother foundation" which is constantly represented symbolically in myth and dream as the Great Mother with her double aspect as Destroyer

\footnotetext{
1 British Journal of Psychology, March, 1920. $\quad 2$ Papers on Psycho-Analysis, p. 158.

8 Analytical Psychology, Ch. Xv.; British Journal of Psychology, Nov. 1919.
} 
and Preserver. The conscious and personal unconscious, on the other hand, contain certain contents of the collective psyche as personal differentiation, that is as personal acquisitions of the individual life as opposed to what is inherited.

In the personal unconscious all the lost memories are stored. New products arise from a new combination of unconscious contents, of which dreams are a common example. In addition to the lost memories and the new combinations, intentional repressions of painful and incompatible thoughts and feelings form an important part of the contents. It is here we find the infantile mind, whereas the primitive aspects belong to the impersonal unconscious.

As a correlate to this, and to distinguish the ego contents of the collective unconscious from the non-ego contents, the Persona is postulated as distinguished from the Individual. The persona is an "excerpt from the collective psyche ${ }^{1}$." The persona was the mask actors wore, through which they spoke. The mask constituted the appropriate appearance for the part played. The persona then is what a man appears to be both to himself and others. A man's type determines his persona to a great extent; he is as he is by nature. The individual, on the other hand, is what he becomes, and is the product of a life-enduring differentiation from what is general and collective and inherited. The persona and the individual are in a sense pairs of opposites. The idea of the persona and the individual comprises as great a difference as that of a person and a personage, save that a personage as often as not attains distinction by conforming to collective opinion and gaining collective approval; whereas the individuated person differentiates himself from what is customary and average, and is only approved when he has given an equivalent to Society in exchange for the exemptions, licenses, or heresies through which he has established his freedom. "The unconscious being collective psyche, is the psychological representation of Society" ; the persona has no relation to it, because being itself collective it is identical with collectivity. Thus the persona is both an excerpt and a component of the general collective psychological function. As it is obvious we have originally nothing but collective material at our disposal, what is individual lies in the uniqueness of the combination of the psychological elements. Individuation follows after the dissolution of the persona into the collective psyche, "whereupon a principle arises that selects and limits the contents that shall now be consciously chosen to be accepted

1 Analytical Psychology, p. 456.

Iung, Individuation and Collectivity (unpublished MS). 
as individual1." Individuation demands the surpassing of the type, first by recognition of what is missing or unconscious in the functions, then by consciously endeavouring to develop what is lacking in order to become free from the childish personality.

In the course of analysis what is unconscious in the mind is gradually made conscious-one gets deeper into the collective psyche-and it becomes obvious that phantasies appear which have no connexion with the actual experiences of the person being analysed, but which are a universal possession dormant from immemorial ages. Thus an impersonal layer of the unconscious is demonstrated, which is also called the absolute. Here the primordial images are discovered; they are the inherited potentialities of human imagination. These form the themes of myths and legends all over the world. In the individual case it is not merely a reproduction of myths once heard, but a new creation of mythology.

Similar images are produced by the insane, and are found in the oldest of existing human records. "The primordial images represent the most ancient universal and deep thoughts of mankind. They are feeling just as much as thought, and might therefore be termed thought-feelings " and expressed differently Jung says the collective unconscious is "the sum of the instincts and their correlates the archetypes of apprehension." He says: "Just as instinct is the intrusion of an unconsciously motivated impulse into conscious action, so intuition is the intrusion of the unconscious content of an 'image' into conscious apperception.... The mechanism of intuition is analogous to that of instinct, with this difference that whereas instinct means a teleological impulse towards a highly complicated action, intuition means an unconscious teleological apprehension of a highly complicated situation. In a way intuition is a counterpart of instinct, not more or less incomprehensible and astounding than instinct itself ${ }^{3}$."

The archetypes of apperception are regarded as "the $a$ priori determining constituents of all experience. Just as instincts compel man to a conduct of life which is specifically human, so the archetypes...coerce intuition and apprehension to forms specifically human"."

"Just as the instincts are deeply covered over by processes of rationalization, so also are the archetypes of apprehension overlaid. But man's conception of the world is just as regular and uniform as his

1 Jung, Individuation and Collectivity (unpublished MS).

$\therefore$ Analytical Psychology, p. 411.

8 British Journal of Psychology, x, No. 1, p. $18 . \quad$ Ibid. p. 19. 
instinctive actions. It is the determining factor of this latter uniformity which is conceived as the archetype, the primordial image."

"The image might be conceived as intuition of the instinct itself, analogous to the conception of consciousness as an internal image of our objective vital processes....Just as we believe instinct to be thoroughly adapted and sometimes incredibly clever, so we must assume that intuition to which instinct owes its existence, must be of extraordinary precision ${ }^{1}$."

The symptoms of neurosis, particularly of compulsion neurosis, and the symptoms of insanity, show atavistic tendencies, such for instance as interest in excreta, which are remnants of an adaptation which was entirely suitable at one stage of our animal or anthropoid existence.

In every psychotic state the unconscious gains a super-value owing to the regression of libido to the collective unconscious, which it reanimates, having first flooded the ego feelings and stimulated a painful self-consciousness, in which the pairs of opposites, megalomania and feelings of inferiority, alternate. When Nebuchadnezzar, identified with the images of the unconscious, dwelt among wild asses, and ate grass, he responded to the inner compulsion to live his unconscious. This case has many parallels in our asylums. I saw a woman recently tossing her head, champing the bit, and pawing the ground. She told me, "I am a horse." In Nebuchadnezzar's day no doubt she too would have been allowed to roam unclothed in the open, her "body wet with the dews of heaven."

Jung has pointed out that in the introversion psychosis of dementia praecox, the strange mythological phantasies indicate the replacement of a recent adaptation to reality by an archaic one. The libido of these patients is taken from the function of reality as a whole, not only from the sexual function, which is now replaced by an "intra-psychic equivalent'." What is peculiar to these patients is the "predominance of phantastic forms of thought" founded upon a pre-occupation of the libido which is normally applied to the ego with the archetypal forms of thought.

In hysterical introversion, on the other hand, the libido designed for the outer object, is introverted and turns to the re-animation of the instincts with the production of auto-erotism. In these pathological states it will easily be seen that the mechanisms approximate to those we have recognised as belonging collectively to the subconscious types, for the

1 British Journal of Psychology, loo. oit. p. 22.

- Psychology of the Unconscious, pp. 152 and 462. See slso The Psychology of Dementia Praecox. 
reason that they are less rational and nearer their instincts. The adaptation that the objective world has demanded from us has necessarily contracted our horizon to the things which it pays us to attend to, but all the same we are aware that when we work in close harmony with our instincts we get the best results. Hence regression of the libido into the unconscious, which produces new phantasies or re-animates the old, is an attempt at self cure (as Freud says of neurosis). The complete cure as $I$ have indicated earlier, lies in a better adaptation to the demands of both worlds of reality, which can only in the last resort be based on the ability to discriminate between the real facts and the unconscious facts. 